\title{
A REVIEW ON VERNIER CALLIPER
}

\section{S. A. OHID* \& B. B. MISHRA}

ITER, Siksha 'O’Anusandhan Deemed to be University, Bhubaneswar, India

\begin{abstract}
This paper discusses the invention of Vernier calliper, its working and applications in various types of jobs. Life in the $21^{\text {st }}$ century completely relies on precise measurement. Each estimation is an examination between an amount we need to know and the standard amount. This examination paper essentially informs us regarding the procedure of estimation and how it changed amid the time. Vernier calliper is a gadget used to quantify the separation between two inverse sides. We have inquired about everything from its history to its present, and we additionally have done some new reasoning on this, with the goal that we can enhance its utilization. So in this, we use scanner which scan the error that is like in dimension, shape which make the vernier calliper more accurate to use.

KEYWORDS: Measuring \& Scanner
\end{abstract}

Received: Apr 16, 2019; Accepted: May 07, 2019; Published: Jun 12, 2019; Paper Id.: IJMPERDJUN2019178

\section{INTRODUCTION}

A term Nogisu means 'a handheld dimensional measuring tool using sliding crank mechanism' in Japanese was the first device that is used in measuring purpose. Around 5000 B.C, the scale technology first came to know by west in the ancient Egypt and later on in China around 1500 B.C [1]. It is believed that the sliding jaw vernier calliper derives from the evolution of ancient scale. Calliper was discovered in ancient China, for extra precision secondary scale was invented in 1631 by French mathematician Pierre Vernier, English mathematician John Barrow developed it for angle measuring purpose then the vernier scale was developed by Portuguese mathematician Pedro Nuns[2]. The vernier calliper is a device used to measure the distance between two opposite sides. It is generally used for precise measurement. The least count of vernier calliper is $0.02 \mathrm{~mm}$ [3].

\section{BACKGROUND}

Calliper was discovered in $9 \mathrm{AD}$, that basically used for measurement. The vernier scale was first invented by French mathematician Pierre Vernier. There are several types of calliper that are used in engineering which make the measurement easy[4].

\section{TYPES AND UTILITY OF CALLIPER}

\subsection{Inside Calliper}

It is used to measure the internal size of an object. 


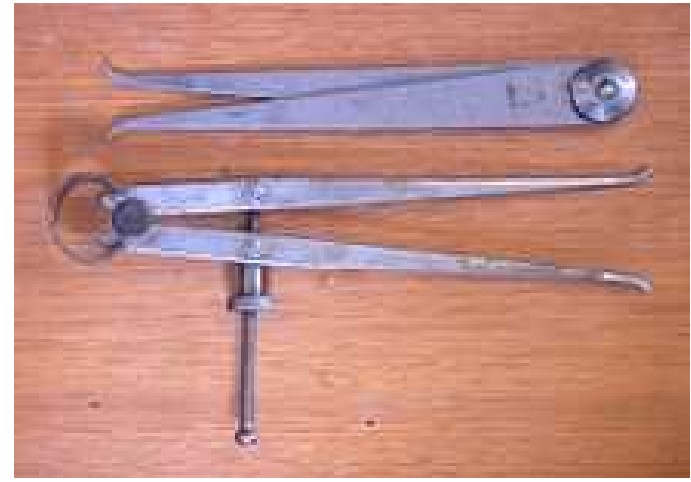

Figure 1

\subsection{Outside Calliper}

It is used to measure the very large distance gap, like the measurement of a large diameter pipe, with high accuracy [5].

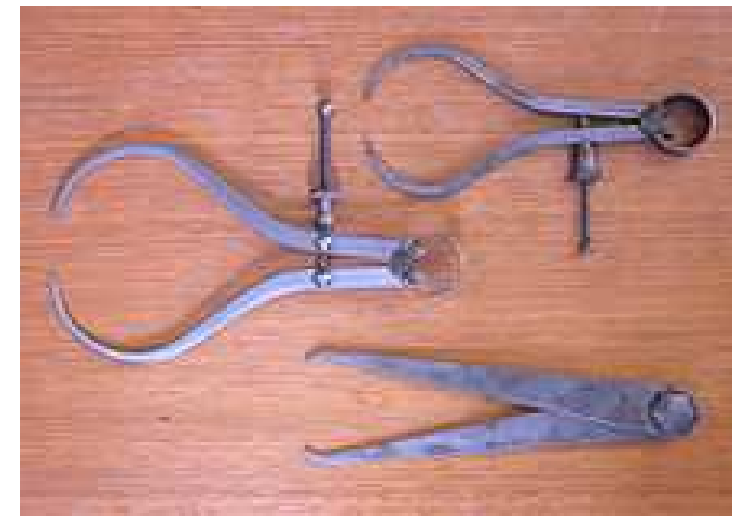

Figure 2

\subsection{Divider Calliper}

It is used to measure or act like a divider, and also used to measure the distance between two points like in a map, as in engineering it is used as scriber [6].

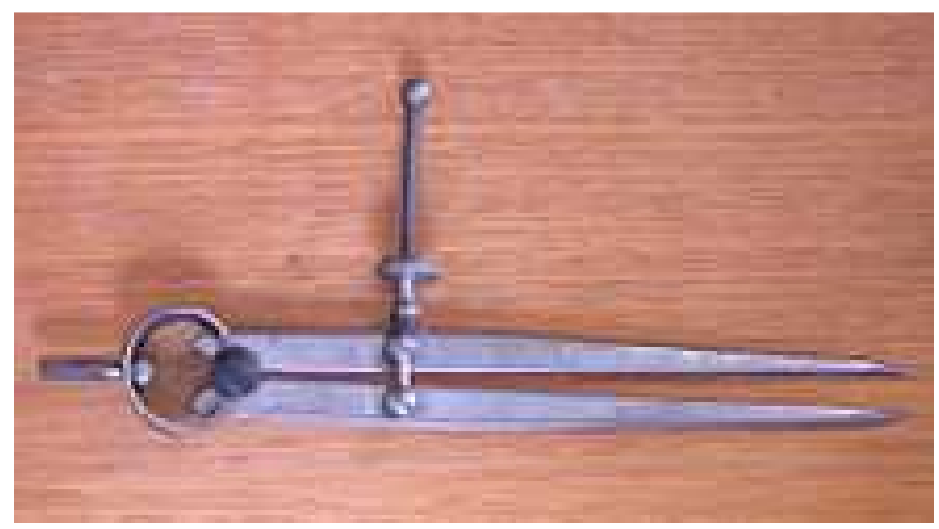

Figure 3 


\subsection{Oddleg Calliper}

Due to its structure and having the sharp edge on its one side, it is used to measure the distance of a work piece.

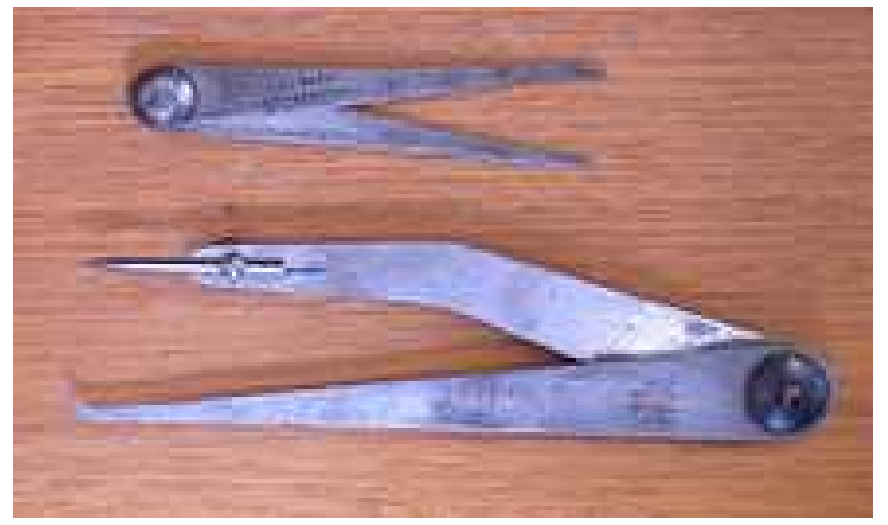

Figure 4

In this above discovery, we got venire calliper which has all property that is mentioned in above and also having some special property like depth gauge which is used to measure the depth [7]. It is used to measure the diameter of a round objects like cylinders because the measuring jaws can be secured on either side of the circumference. It has both fixed main scale and moving vernier scale [8]. The main scale is inscribed in millimetres while vernier scale is used for more precise measurement in comparison to standard ruler $[9,10]$.

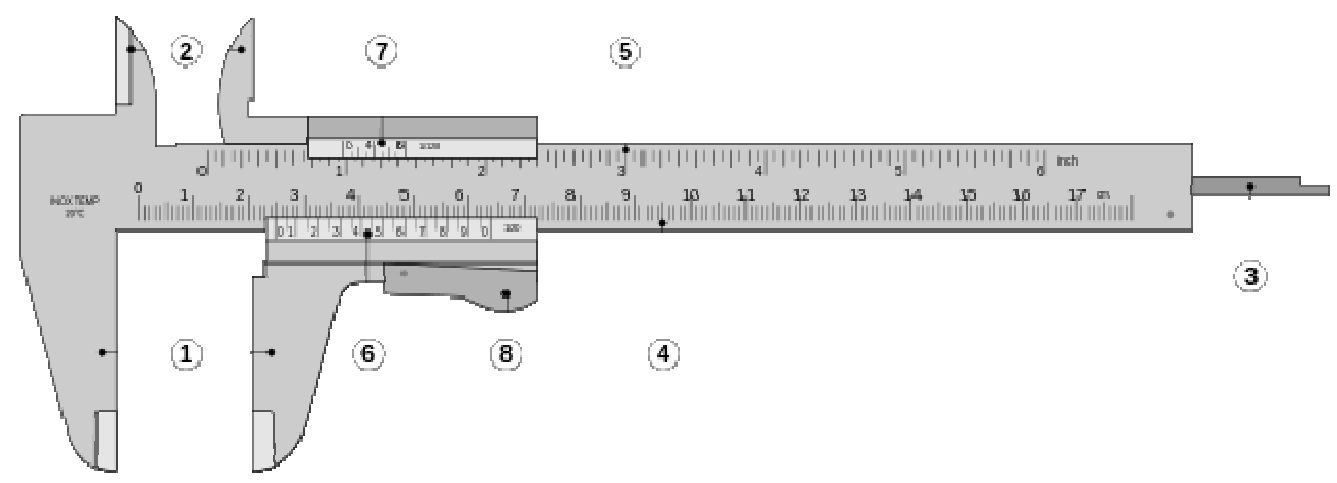

Figure 5

1. Outside large jaw

2. Inside small jaw

3. Depth rob

4. Main scale(metric)

5. Main scale(imperical)

6. Venire scale(metric)

7. Venire scale(imperical) 


\subsection{Application}

- Used in education purpose.

- Used in medical sector.

- Used in aerospace sector.

- Used in scientific labs for research purpose.

- It has machine shop application.

- It has locksmithing application.

\subsection{Advantages}

- Accuracy and precision

- Integrated scales

- Versatility

- Durability

- Low cost

\subsection{Disadvantages}

- Good eyesight is required

- Complex reading

- More accurate tools are available

\section{CONCLUSIONS}

Finally, after the investigation of venire calliper, we infer that it is most exact gadget which works with outmost exactness; however the principle issue is its unpredictable structure which makes it hard to take the readings. In view of that numerous researcher are endeavouring to extemporize it, and some have done stop a well in this field like some researcher have enhanced it with new systems of taking readings, which influence handlings of gadget to stop simple. For instance, one of researcher make dial Vernier calliper which on taking perusing demonstrates the estimation esteem, additionally one have advanced a computerized Vernier calliper, which demonstrates the estimation esteem naturally on putting the calliper on the materials that is, measurement is required to gauge. As of late, one of researcher makes a development that to gauge the vast separation by the assistance of ultrasonic waves. Along these lines, we have thought of that to make Vernier calliper fill in as a scanner, so it can without much of a stretch recognizes the physical blunder, like in estimating measurement or its shape. 


\section{REFERENCES}

1. X. Zhang, D. Peng, X. Chen, and X. Liu, "Development of a new angular displacement sensor based on principle of vernier caliper," in Third International Symposium On Precision Mechanical Measurements, PTS 1 AND 2, 2006, vol. 6280, no. $1 \& 2$.

2. T. Connelly and A. Dixon, "Surgical Pearl: Use of digital Vernier calipers for measurement of lesional and excisional dimensions,” J. Am. Acad. Dermatol., vol. 56, no. 1, p. 146, Jan. 2007.

3. S.-Y. Jiang, C.-W. Huang, Y.-L. Lo, and K.-H. Cheng, "Vernier Caliper and Equivalent-Signal Sampling for Built-In Jitter Measurement System," IEICE Trans. Fundam. Electron. Commun. Comput. Sci., vol. E92A, no. 2, pp. 389-400, Feb. 2009.

4. Huang, H. C., \& Lee, Y. D. (2017). A Study of Indigenous Measuring Factors for Employer Brand Attractiveness in Taiwan: Comparative Analysis of Academy and Industry Experts. IMPACT: International Journal of Research in Business Management (IMPACT: IJRBM), 5(11), 11-20.

5. K.-Y. Lee, C.-F. Huang, K.-N. Huang, S.-S. Huang, and M.-S. Young, "Two-Frequency Ultrasonic System with Direct Digital Frequency Synthesizers and Vernier Caliper Phase Meter for Measuring Air Temperature," SENSORS Mater., vol. 24, no. 7, pp. 397-412, 2012.

6. K.-Y. Lee, C.-F. Huang, S.-S. Huang, K.-N. Huang, and M.-S. Young, “A High-Resolution Ultrasonic Distance Measurement System Using Vernier Caliper Phase Meter,” IEEE Trans. Instrum. Meas., vol. 61, no. 11, pp. 2924-2931, Nov. 2012.

7. M. I. Etingof, “Modern vernier caliper,” Meas. Tech., vol. 55, no. 8, pp. 890-893, Nov. 2012.

8. N. Best, S. Best, D. Loudovici-Krug, and U. C. Smolenski, "Measurement of Mandible Movements Using a Vernier CaliperAn Evaluation of the Intrasession-, Intersession- and Interobserver Reliability," CRANIO-THE J. Craniomandib. Pract., vol. 31, no. 3, pp. 176-180, Jul. 2013.

9. Raghavan, N., \& Panboli, S. (2018). Measuring Emotional Intelligence of School Children-A Pilot Study. IMPACT: International Journal of Research in Humanities, Arts and Literature, 6(1), 207-218.

10. D. Naidu and T. J. Freer, "The evidence supporting methods of tooth width measurement: Part I. Vernier calipers to stereophotogrammetry," Aust. Orthod. J., vol. 29, no. 2, pp. 159-163, Nov. 2013.

11. C.-F. Huang, C.-Y. Liu, and Y.-C. Chen, "A Novel Successive Approximation Register ADC Based on Vernier Caliper Design," in Proceedings Of The 2nd International Conference On Intelligent Technologies And Engineering Systems (ICITES2013), 2014, vol. 293, pp. 299-305.

12. S. Sharma, S. L. Thakur, S. K. Joshi, and S. S. Kulkarni, "Measurement of gingival thickness using digital vernier caliper and ultrasonographic method: a comparative study,” J. Investig. Clin. Dent., vol. 5, no. 2, pp. 138-143, May 2014. 
